\begin{tabular}{ll} 
INTERNATIONAL RESEARCH JOURNAL OF MULTIDISCIPLINARY TECHNOVATION (IRJMT) \\
$\begin{array}{l}\text { MAPLE TREE } \\
\text { JOURALS }\end{array}$ & $\begin{array}{l}\text { http://www.mapletreejournals.com/index.php/irjmt } \\
\text { ISSN 2582-1040 }\end{array}$ \\
\hline
\end{tabular}

\title{
IOT Based Smart Rodent Detection and Fire Alert System in Farmland
}

\author{
T. Sowmika ${ }^{1}$, L. Rohith Paul ${ }^{2}$, G. Malathi ${ }^{1}$ \\ ${ }^{1}$ School of Computer Science and Engineering, Vellore Institute of Technology, Chennai-600127, Tamil Nadu, India. \\ ${ }^{2}$ School of Electronics Engineering, Vellore Institute of Technology, Chennai-600127, Tamil Nadu, India.
}

*Corresponding author E-Mail ID: sowminaidu710@gmail.com

DOI: https://doi.org/10.34256/irjmt2031

\begin{abstract}
Agriculture is playing an important role in the development of a country. In this work, a smart and safe agriculture system is proposed that would notify the farmer about the deficit of moisture in the soil, snakes concealed under the soil, passers crossing the farm at odd times using IOT. The flame sensor and humidity sensor are deployed in farms in order to find humidity and detect fire attack. It is virtually hard for everyone to monitor the growth of plants in a large agricultural farmland. The approach that can be used to solve this problem is using IOT based sensor networks to assist the current traditional methods that are used by the farmers in order to improve their efficiency. This approach in turn significantly reduces the carbon release from agriculture which in turn will have a positive impact in solving our climate change crisis. The Indian economy accepts security in terms like protection from attacks of rodents in fields. Hence, this work focuses on raising a smart agriculture using automation and IOT technologies.
\end{abstract}

Keywords: Flame Detection sensor, Ultrasonic sensor, PIR Sensor, Buzzer, Soil moisture sensor, Raspberry Pi, Cloud networking

\section{Introduction}

Agriculture is one of the most essential field only in India but in any part of the world. This work is intended to provide solutions to the problems like identification of rodents and preventing fires. The sensor networks that are deployed in the field sense the data from the different sensors and then transmit it to the cloud using Wi-Fi module. This scheme monitors the abundance of temperature, humidity, soil moisture and uses ultrasonic sensor, flame detection sensor, PIR sensor and a buzzer. If the sensor values are deviating from the already set threshold values, then the relay goes to ON condition, and the relay switches ON the motor pump which will pump the water until the sensors reaches the required values. The importance of this work highlights the fact that the loss of food crop yield from the farmland could be minimized. The automation can be brought in agriculture field in order to overcome these issues.

\section{Literature Survey}

Smart irrigation system is discussed [1] to save water. The authors have suggested ways to provide water automatic watering to plants, gardens and park in order to provide water automatically. The water is supplied based on the requirements about which plant needs more water and which plants do not. For these to be in action, microcontrollers are used to check the requirements and to obtain data from soil such as moisture and also temperature using temperature sensor. Apart from smart irrigation, weather monitoring system is also considered in [2]. Certain 
parameter like soil moisture, humidity, temperature, rain fall, wind speed, radiation, and wind direction are including for measurement. The dryness of the soil is obtained using the soil moisture sensor. The evaporation rate of soil is measured using the rain sensor. If the value obtained from soil moisture goes down from the user defined values, it starts watering the plants and it also sends a message using SIM300. Another device called anemometer is used for mapping a wind speed.

A step towards smart farming is introduced [3] such that a low-cost system so that anybody can use it. The system uses raspberry-pi, soil moisture sensor and GSM Module. The moisture content of the soil is measured for dryness range. If the dryness of the soil is detected it will automatically notify to the registered device of the farmer. It also sends an email to the registered email address. Local Shortest Path is used to control the wireless sensor network.

A farming method was developed [4] by measuring the $\mathrm{PH}$ rate of the soil to find the dryness and also temperature and water level is also monitored. Here, they are used raspberry pi, LCD to display current status and GSM module, soil moisture and temperature sensor. Now when PH rate goes down from certain threshold value it will notify the user to improve farming method and provides suggestion to the farmer based on $\mathrm{PH}$ value and also to measure temperature of soil using LM35.

Wireless monitoring [5] of temperature, soil moisture and humidity is implemented using Zigbee in agriculture. For the hardware support, 8-bit AVR and blue tooth is used for low cost power consuming so that anybody can use it. With increase in population over time, the scarcity of water has increased profoundly. There becomes a need to effectively utilize the water resource. The availability of water at a particular depth can be sensed through the frequency response from the soil. Using these are inputs the irrigation system [6] can be automated.

In order to automate the agricultural process in zones where availability of water is limited [7] has designed ways for usage of water by plants efficiently. The quantity of water to be delivered is taken care by the algorithm which uses microcontrollers and sensors which obtains the input. When compared to the tradition agricultural methods deployed on water quantify, this system was tested and it produced $90 \%$ results. There is an alarming outburst in population. The current yield from agriculture may not be sufficient to meet the growing demands. It requires the yield from agriculture to be doubled [8]. There are many obstacles in achieving these goals. The climatic change Is one of the major attributes that hinders the process. Due to population explosion most of the land region required for farming has been converted into dwelling places resulting in land degradation too.

Since water crisis is a threatening issue, there is a need to design a decision support system [9] which efficiently reduces water usage and also cost effective. The same may be used to improve the water sources also. In some cases, fuzzy logic was employed to assess the crop conditions thereby providing a ground for deploying smart irrigation system.

The utilization of WSN system in agriculture has been in existence. Sensors was used later to improve the vigilance of agriculture environment.

With the advances of WSN system, the irrigation system is enhanced using the sensors. These sensors are normally used for the estimation of soil moisture. The challenge in assessing the volumetric level of soil is overcome by the usage of these sensors. The WSN and Wireless Sensor and Actuation Network (WSAN) technologies are being used along with the sensors to detect the water and soil content level.

Adapting to WSAN based systems in agriculture has assisted in monitoring the agriculture in a simpler and low cost one. Thus, it improved in the management of fresh water level and 
usage. This sensing technology along with WSN systems provides a better chance in monitoring the changes in agriculture. Though the smart technology used in agriculture is impressive, there are few observed disadvantages in the use of it in agriculture as it does incur a lot of costs. Certain issues have to be tracked properly in order to attain the full benefit of it.

\section{System Architecture}

The current architecture uses the raspberry pi which acts as the processor and a Wi-Fi module which allows the raspberry pi to connect to the cloud and push the sensor values at frequent interval. The mixture of temperature, humidity, $\mathrm{pH}$, flame and soil moisture sensors are together interfaced to the input pins. Water pump and buzzer are interfaced to the output pins. This method has many advantages over the existing methods - It increases efficiency and competitiveness. We use, DHT11 which is a low cost and power efficient humidity sensor and LM35 temperature sensor which gives high accuracy and has low self-heating property. These sensors deliver the results instantly.

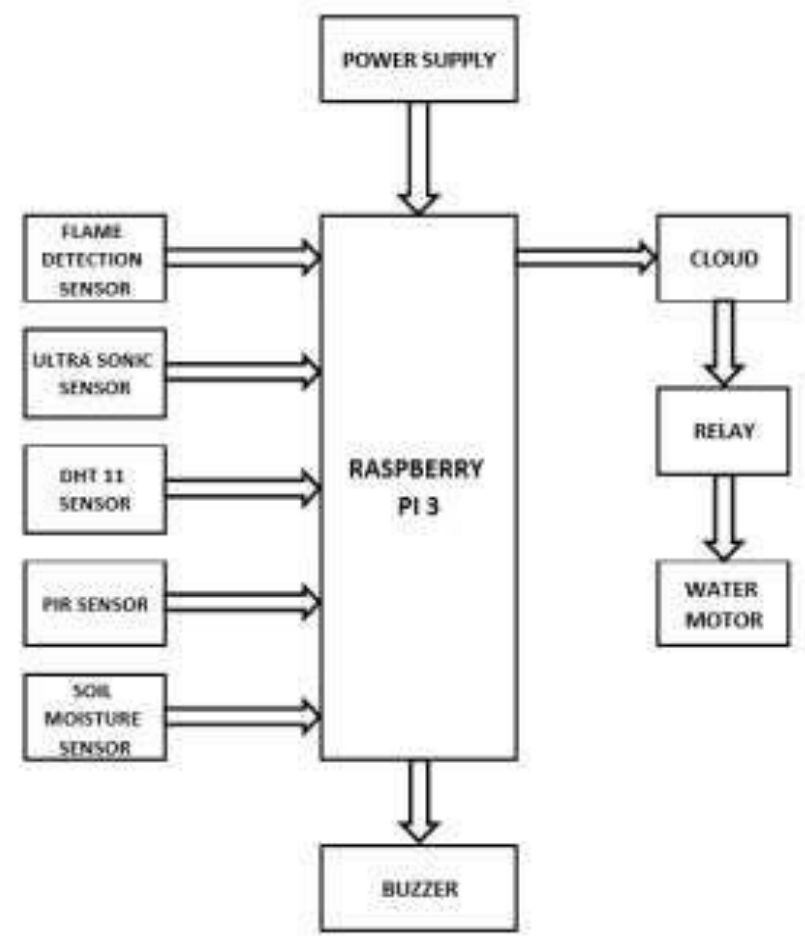

Fig 1. System Architecture using raspberry pi

System architecture as represented in Fig.1 is an ethereal model that defines the structure, behaviour, and the outlook of the system. Sensor networks collects the data from different sensors and then transmits the values to the main server using the $\mathrm{Wi}-\mathrm{Fi}$ module. This scheme monitors using the abundance of temperature, humidity, soil moisture, ultrasonic sensor, flame detection sensor and PIR sensor and a buzzer. Initially the optimal conditions that are required to grow the crop efficiently are set. Then, the values that are obtained from the sensors and then compared with these optimal values, if they deviate from the optimal values more than a certain threshold the relay is powered ON. The relay then switches ON the motor to water the crop. The motor remains in ON state until the values obtained by the sensors is in the required range for the ideal growth of the crop. When the required values are reached, the relay naturally switches off the motor. 
The flame detection sensor is used to detect fires in the farm. Fig. 2 represents the flame detection sensor. It takes the data from field and sends it to raspberry Pi. If there is a fire in the farm, a cloud communication platform will automatically send a message to farmer's registered mobile number and email address. At the same time, it turns the buzzer ON which is shown in Fig 3

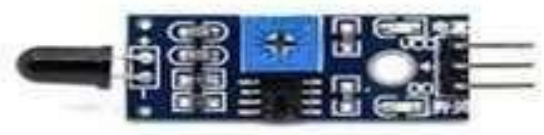

Fig 2. Flame Detection Sensor

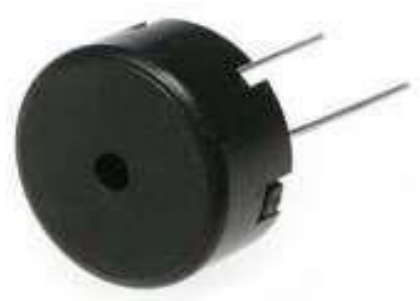

Fig 3. Buzzer

Using ultrasonic sensor, as shown in Fig.4, the distance of an object is calculated by using sound waves. Whenever, any impediment comes ahead of the ultrasonic sensor the sound waves will mirror back in the form of echo and provoke an electric pulse.

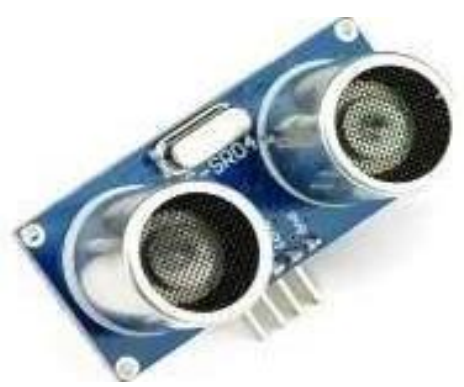

Fig 4. Ultrasonic Sensor

The Soil moisture sensor is used to obtain the soil moisture level of the field, if the moisture level is below the optimal level, then the water motor is turned ON using the relay, and if the soil moisture value reaches the optimal level, the relay is turned OFF to switch off the motor. Fig.5 shows the soil moisture sensor.

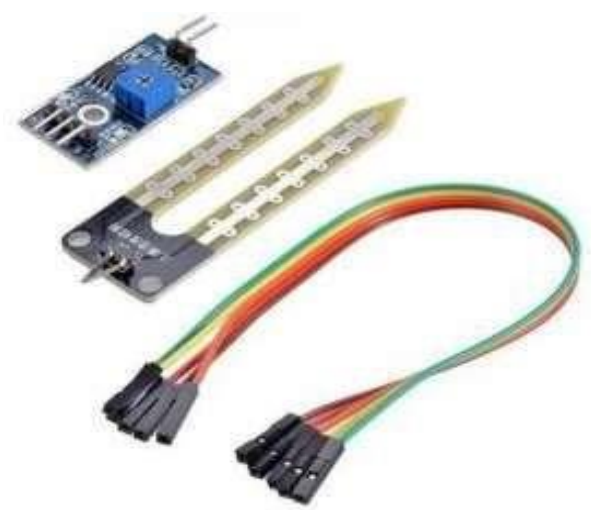

Fig 5. Soil Moisture Sensor 
PIR sensor is used to detect any warm moving object that enters into the field. It can detect rodents moving around the field within almost $10 \mathrm{~m}$ from the sensor. They are essentially made of a pyro electric sensor, which can detect levels of infrared radiation. PIR sensor is shown in Fig.6

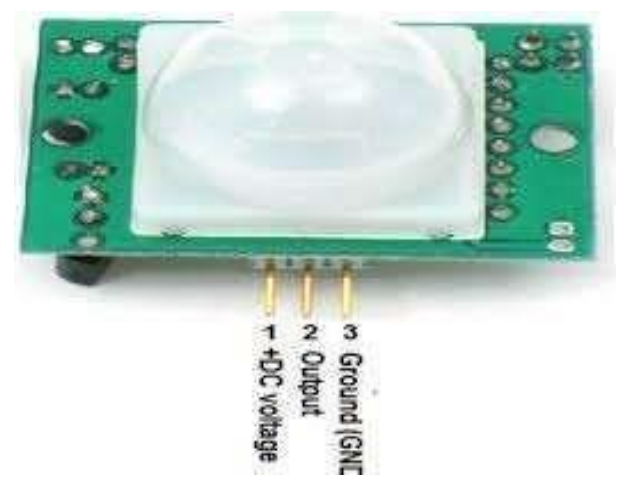

Fig 6. PIR Sensor

\section{Results and Discussion}

The raspberry pi hardware module uses the Raspbian OS and runs python scripts which enable and collect sensor values from ultrasonic sensor, PIR sensor, soil moisture sensor, flame detection sensor, DHT11 sensors and then uses scripts which control the relay which in turn controls different actuators like water pump and buzzers. The Wi-Fi module is used to send the sensor values to a cloud service platform which analyze the data and perform the required operations like turning on the motor and buzzer. The cloud service platform is also used to send alerts to the farmer on the condition of the crop. By using the PIR sensor any pests (mammals) rodents or boars can be detected and farmers can be altered so that they can take an appropriate action before the pest destroys the crop.

\section{Conclusion}

The primary objective of this work is to ensure a safe environment to farmers while working in the field and preventing pests from destroying the crop. Previously, the farmer had to monitor his field frequently for pests which can destroy his crop which can incur lot of financial loss to the farmer, but with this project the farmer can monitor his crop with the help of an application and in case any pest enters his crop or a fire occurs in his farm, he will be alerted instantly so that he can take proper action saving him lot of time and the money that he invested in the crop. And with the automatic water pump, water is dispensed to the field by assessing the moisture level thereby indirectly improving the yield and saving lot of water.

\section{References}

[1] S. Darshna, T. Sangavi, S. Mohan, A. Soundharya, S. Desikan, Smart Irrigation System, IOSR Journal of Electronics and Communication Engineering (IOSR-JECE), 10 (2015) 32-36.

[2] P.A. Bhosale, V. V. Dixit, Water Saving- Irrigation Automatic Agricultural Controller, International Journal of Scientific \& Technology Research, 1 (2012) 118-123.

[3] K.S. Chandan, B. Pramitee, (2015) A Low-Cost Smart Irrigation Control System, In Proceedings of the International Conference on Electronics and Communication System, IEEE, 26-27 
[4] E. Sowmiya, S. Sivaranjani, Smart System Monitoring on Soil Using Internet of Things (IOT), International Research Journal of Engineering and Technology (IRJET), 4 (2017) 1070- 1072.

[5] C. H. Chavan, P.V. karande, Wireless Monitoring of soil Moisture, Temperature \& Humidity Using Zigbee in Agriculture, International Journal of Engineering Trends and Technology (IJETT), 11 (2014) 493-497.

[6] J. F. Posada, J. J. Liou, R. N. Miller, An Automated Data Acquisition the Characteristics of a Soil Moisture Sensor System for Modeling, IEEE Transactions on Instrumentation and Measurement, 40 (1991) 836-841.

[7] J. Gutiérrez, J. F. Villa-Medina, A. Nieto-Garibay, M. Á. Porta-Gándara, Automated Irrigation System Using a Wireless Sensor Network and GPRS Module, IEEE Transactions on Instrumentation and Measurement, 63 (2013) 166-176.

[8] F. Y. Narvaez, G. Reina, M. Torres-Torriti, G. Kantor, F. A. Cheein, Fernando AuatCheein, A Survey of Ranging and Imaging Techniques for Precision Agriculture Phenotyping, IEEE/ASME Transactions on Mechatronics, IEEE, 22 (2017) 2428-2439.

[9] M. Kang, F. Y. Wang, From Parallel Plants to Smart Plants: Intelligent Control and Management for Plant Growth, IEEE/CAA Journal of Automatica Sinica, 4 (2017) 161-166.

\section{Acknowledgement}

We would like to thank the management of Vellore Institute of Technology, Chennai, India for their support and encouragement.

\section{Funding}

This study was not funded by any grant

\section{Conflict of interest}

None of the authors have any conflicts of interest to declare.

\section{About The License}

The text of this article is licensed under a Creative Commons Attribution 4.0 International License

\section{Cite this Article}

T. Sowmika, L. Rohith Paul, G. Malathi, IOT Based Smart Rodent Detection and Fire Alert System in Farmland, International Research Journal of Multidisciplinary Technovation, Vol 2, Iss 3 (2020) 1-6.

DOI: https://doi.org/10.34256/irimt2031 